\title{
Progressive bifocal chorioretinal atrophy
}

INSERM

\section{Source}

INSERM. (1999). Orphanet: an online rare disease and orphan drug data base.

Progressive bifocal chorioretinal atrophy. ORPHA:75373

Progressive bifocal chorioretinal atrophy (PBCRA) is an early-onset chorioretinal

dystrophy characterized by large atrophic macular and nasal retinal lesions, nystagmus,

myopia, poor vision, and slow disease progression. 